Tahmasib Kh. Fataliyev ${ }^{1}$, Nigar T. Fataliyeva ${ }^{2}$

DOI: $10.25045 / j p i s . v 08.11 .13$

${ }^{1,2}$ Institute of Information Technology of ANAS, Baku, Azerbaijan

12depart3@iit.ab.az, ${ }^{2}$ depart15@iit.ab.az

\title{
ISSUES OF FORMATION AND APPLICATION OF E-MEDICINE
}

\begin{abstract}
The paper is devoted to the topical issues of formation of e-medicine. As an integral part of e-science and e-health, the problems of e-medicine and international support were investigated and main directions of its development are shown. The role of e-medicine was specified in realization of $4 P$ personalized medicine and disease rehabilitation.
\end{abstract}

Keywords: e-science, e-health, e-medicine, health 2.0, consumer-oriented medicine, 4P medicine concept, rehabilitation of child neurological diseases.

\section{Introduction}

Information society building has become a driving force of the development in all spheres. The use of information communication technologies (ICT) constituting the foundation of the formation of information society has accelerated the development in spheres of science, education and healthcare. In accordance with $\mathrm{C} 7$ clause of the Action Plan of World Summit on the Information Society (WSIS), the formation of e-science, e-education and e-health (e-medicine) has become a topical issue in our country. Thus, alongside with informatization, the level of ICT development and its problems in mentioned spheres has necessitated the shift to the policy of formation of unified and favorable information space, and the development of information resources and infrastructure for the use of the structure of each sphere. Hence, the aim of such implemented projects is to provide an access to resources of scientific, technical, educational, healthcare, medical information and computation spheres and the joint activity of the collectives of corresponding spheres and separate individuals via high-speed Internet network with information-communication infrastructure [1].

In "National Strategy on the development of information society in the Republic of Azerbaijan for 2014-2020 years" adopted with the Order of the President of the Republic of Azerbaijan dated 2 April 2014, it is mentioned that ICT has instilled new values in the public administration, science, education, healthcare and other spheres and become an integral part of socio-economic relations and the driving force of the development of society. The expansion of ICT application in healthcare, the provision of medical workers and patients with latest medication information and data by using its facilities and the contribution into development of timely, accessible and effective medical services for everyone are among primary goals of e-medicine. The following is considered to be carried out for the formation of e-healthcare in our country:

- Establishment and development of National Healthcare network providing the connection of all medical personnel and medical institutions to secure and broadband network;

- Development of electronic health card system and provision of all age groups with electronic health card;

- Expansion of application of medical information systems and connection with electronic health card system;

-Establishment of medical resources for public use;

- Development of telemedicine;

- Encouraging the improvement of ICT knowledge of medical staff.

ICT plays an important role in development of modern medicine and healthcare. It is known that the following tools are crucial for such development:

- computers, servers and other technical tools;

- tools of data generation, compilation, storage, processing and search;

- design tools of databases, graphic systems, multimedia and automatized medical job places; 
- computerized equipment for diagnostics and treatment;

- microprocessor modules for medical equipment;

- global and local networks.

As in other sectors, the process of informatization in healthcare is oriented towards the establishment of unified medical information space facilitating the communication among scholars and medical personnel, utilization of archives and libraries of medical knowledge and technologies, as well as the use of active equipment directly at work place and in real time regime. As a result, the advancement in informatization of healthcare will turn medical knowledge into public heritage.

\section{E-medicine as an important direction in formation of information society}

E-medicine which plays an important role in the formation of information societycan be considered as an integral part of e-healthcare due to its administrative function.

International organizations carry out important tasks for the development of e-science and its various fields, as well as e-healthcare and e-medicine. Such that, they are regularly engaged in addressing the existing problems in this field, carry out different projects and programs and organize international conferences, forums and symposiums. It can be shown as an example that notable international organizations, such as ITU, UNESCO, UNDP and UNCTAD, regularly monitor the addressing of problems envisaged in WSIS Action Plan with interested parties (in healthcare, WHO - World Health Organization), and host forums and competitions. Various works carried out in e-healthcare direction of C7 clause of WSIS Action Plan and the solution of new problems have been discussed in 6 of annual forums successively held starting from 2006. Among the other issues envisaged in AP, the engagement of publicity in global health issues, utilization of social media facilities, the expertise and problems in this sphere were also discussed in the ITU Forum held in Geneva on 25-29 May 2015 [2]. It is to be noted that, e-medicine occupied a special place in addressing the discussed problems.

The application of e-science in various scientific fields facilitate the formation of specific online environments and hence, the emergence of e-medicine, e-geography, e-chemistry, e-history, and e-astronomy.

It is known that the search of data compiled during medical examinations, treatment and surgeries become more complicated, and in most cases, the data is lost. All this adversely affects the operative decision making and the development of medical science, and leads to wrong diagnoses, shortening of human life, higher rates of morbidity. E-medicine as such creates new opportunities for creating e-health cards, improving medical diagnostics and treatment processes by using sensor networks, for the analysis of log-files from psychological point of view, compilation, analysis and diagnostics of medical data, the organization of e-board of doctors, and e-medicine consultation.

Informatization and formation of information provision is among the priority directions of e-science and e-healthcare. The goal of informatization is the facilitation of favorable environment for meeting users' demand for information by applying ICT. Methods and tools of management and the advanced ICT constitute the foundation of informatization. In this regard, the formation of reliable and effective infrastructure complying with goals of corresponding spheres, application of standard methods of the access to corporate data, establishment of various information resources and improvement of convenient tools of use of such data are important measures adopted.

With the growing significance of the role of information in modern society, several important notions have emerged. Among those, the notion of "medical data" is of special interest.

Medical data - is the data regarding the population health, healthcare system, medical science and related sciences, and environment. The following are distinguished in the structure of medical data:

- scientific data; 
- business data: business news, normative acts, statistical data, advertisement, data on manufacturers and consumer of goods and services in medical market, etc.;

- consumer data: medical data designated for population.

Electronic publications constitute a special class of scientific and medical data thatare characterized with the capability of storage of unlimited volume of data.

The traditional fields of information services are scientific medical libraries.

Various databases exist on medical topics such as Aidsline, Bioethicsline, Cab, Cancerlit, Chemical Identification File, Chemline, Diogenes, Embase, Embl, Hazardous Substances Databank, Histline, MEDLINE, Phytomed, Psicinfo.

Informatization of healthcare envisages the establishment of unified information space comprising all medical systems. Unified information space is a complex databases and archives, the technologies of their establishment and use, information-communication systems and networks which operate on the basis of unique principles and general rules, meet the information demand of organizations and citizens and facilitates their mutual relations. The notion of unified information space as a territorial notion considering the unification of information of enterprises located in a specific area. Its main components are as following:

- organizational structures providing its operation and development, including the tools of data compilation, processing, storage, dissemination, search and transmission;

- data, information stored in data carriers, and information resources storing knowledge;

- mutual communication tools providing the shift of citizens and organizations to information resources and storing software-technical tools and organizational-normative documents.

Unified information space of medical data in medical informatics and unified information space of healthcare system, and the similar notions of general medical information space and general medical statistics are distinguished.

Unified information space of medical data is a metasystem based on the computer network of medical information systems integrating the data on patients on treatment and autonomously operating in enterprises of different level.

Hence, e-medicine is shaped as a result of various integral parts such as infrastructure, data generation, compilation, storage, processing, search, analysis, transmission, and presentation .[3].

\section{International initiatives accelerating the development of e-healthcare and e-medicine}

We consider the scope of influence of the support in this sphere and the perspective issues using the example of the European Union (EU) [4].

The healthcare policy of the EU covers the following:

-referring to tools and services capable to improve the prevention, diagnosis, treatment, monitoring and management by using ICT in healthcare;

-improving the accessibility and quality of medical services, hence, contributing to the whole society by making the healthcare sector more productive;

-information and data sharing among those providing healthcare services, hospitals, healthcare professionals and healthcare information networks; electronic health records; telemedicine services; portative devices for patient monitoring; software for planning surgery rooms, robotized surgery and virtual physiological tests on human.

The following achievements of the EU on e-healthcare sector must be noted in particular:

- improving the health of citizens by making vital information publicly available among countries with the help of e-medicine;

- making e-medicine an integral part of healthcare policy and improving the quality and accessibility of healthcare by comprising the political, financial and technical strategies of EU countries; 
- making e-medicine tools more effective, more convenient for users and wider in use by engaging experts and patients in strategies, projects and implementation.

The EU carries out the coordination on the following directions in e-medicine:

- several potential obstacles in the sphere of e-medicine can only be eliminated at national and regional level, however, the coordination at the EU level facilitates the coordinated approach;

- patient security, political administration, engagement of healthcare experts and mutually understandable terminology are more importance spheres of the EU;

- alongside, the EU support for projects guarantees the latest novelties and information in this sphere.

Main initiatives of the EU for supporting e-medicine are oriented towards the following directions:

- ICT;

- standardization;

- medical scientific-research;

- support for scientific-research;

- telemedicine;

- telecommunication networks, including e-medicineprojects,databases.

- Medical devices;

- European health insurance card.

The EU support for e-healthcare (e-medicine) projects can be divided into three parts: 1) project financing; support for events on awareness raising (including annually held highly regarded e-medicine conferences) and advanced expertise exchange, 2) information provision for policymaking, and 3) establishment of network building structures. Several projects pertaining to emedicine are jointly financed within the framework of various programs of the EU.

ICT applications and Cybersecurity Division of International Telecommunications Union (ITU) provides recommendations on e-medicine strategies and policies, creates instructions and training materials on the application of e-medicine and assists the implementation of technical cooperation projects, and hence, supports the developing countries [5]. With more effective application of ICT, works are being carried out in following directions in order to improve the accessibility of medical services:

- national e-medicine strategies;

- support for the use of mobile technologies for the prevention of noninfectious diseases and improvement of treatment;

- support for works of the Commission on Information and Accountability for woman and child health of ITU;

- registry of e-medicine projects (it is a joint initiative by ITU and WHO carrying out the compilation of operative e-medicine projects in unified registry).

Hence, issues on supporting e-healthcare (e-medicine) considered in the example of EU and ITU opens new opportunities for accelerating the formation of this sphere in our country.

\section{Role of e-medicine in formation of personalized medicine}

Development trends of modern medicine are related to the achievements of P4 medicine based on the principles of personalized approach to human health. Therefore, ample opportunities have emerged for the establishment of person-oriented personalized medicine based on the processing of large-volume data emerged as a result of biological and medical research and compiled from social networks by Big Data and other intellectual analysis technologies (Figure 1). This approach was first proposed by Lee Hood, the professor of the university called $P 4$ medicine. The central idea of $4 \mathrm{P}$ concept is to focus all facilities of fundamental science on a specific patient [6]. This concept comprises the following: 
- predictive-revealing the tendency for development of the disease;

- preventive-disease prevention or lowering the risk of disease development;

- personalized-personalized approach to each patient considering his/her genetic, biochemical and physiological features;

- participatory-active participation of human in prevention and treatment of possible diseases.

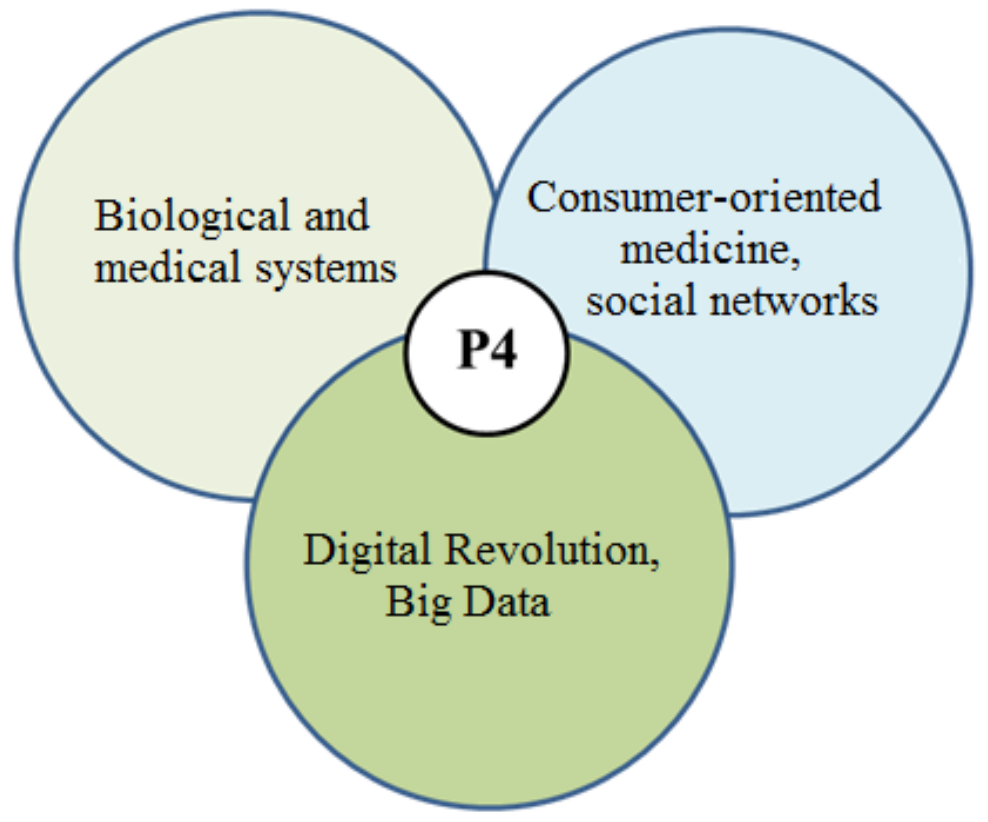

Figure 1. P4 medicine model

The development of the science of informatics, especially the tools of data processing, graphical user interface and geographical information systems based on web technologies, mobile technologies, smartphones, tablet computers and other portative gadgets play an important role in development of e-medicine. It is known that social cooperation technologies, such as social networks, blogs and wiki-pages, boost the emergence of several online communities -Facebook, Twitter, LinkedIn, MySpace and Wikipedia, which facilitate the mutual communication among people with similar experience and interests. Such new technologies have created new opportunities for the expansion of public participation in e-medicine.

At the same time, development of the Internet and web-technologies, ongoing phenomenon of digitalization has fostered the emergence of Health 2.0, Medicine 2.0, etc. alongside with Science 2.0 and Education 2.0. Those are characterized by the types of activity based on scientific exchange and cooperation with the application of ICT, Web 2.0 technology, in particular. The use of cooperation technologies, such as wiki, blog and video-journal, plays an important role in sharing ideas, information or scientific results. The common feature of the scope of coverage of these notions is to achieve public accessibility, shorter periods of publication (for example, via scientific wiki pages), rapid feedback (for example, by using social networks) or higher degree of participation and cooperation (for example, in virtual research environments).

Social networks play a crucial role in the development of e-medicine. Several medically oriented social networks have emerged and develop in Internet. Web technologies turn social medical networks and societies into the effective environment for supporting the healthcare as a thorough and high-quality source of information on new medical methods and diagnoses, medicaments and their use.

The following can be shown as example of Internet services that are most important in healthcare sector: 
- teleconferences;

- information support services for patients;

- advertisement of medicaments and medical services;

- tele-medical meetings of board of doctors and consultations of doctors;

- set of tools for everyday work tasks of doctors: learning the outcomes of analyses, monitoring of appointment execution, issuing appointments;

- work with medical literature, search in libraries, article exchange with experts;

- study and exchange of databases;

- tracking the patient status;

- organization of joint scientific research;

- telemedicine, etc.

The above-mentioned services play an important role in realization of personalized P4 medicine oriented to a specific person.

\section{Application of electronic medicine in rehabilitation of child neurological diseases}

The number of cases of disability among children and teenagers is observed to grow. The problem of rehabilitation of disabled children remains to be among very topical and debated issues.

Child cerebral palsy. The first place among the causes of child disability is attributed to the diseases of nervous system and sense organs, and child cerebral palsy (CCP) is included in this group [7]. CCP is a group of diseases related to the damaged nervous system, dysfunctionality of movement and muscular system, movement coordination disorders, speech impairment, and intellectual growth retardation. The intensity of these defects varies from moderate to severe cases, which adversely impacts the process of adaptation of children with cerebral palsy to environment and their overall living conditions. It is to be noted that the development of a child with physical disabilities as an individual is more effectively realized during the state of integration. Social integration envisages the adaptation of a child to the system of social relations and mutual links within the environment to which a child is integrated. The mutual communication of children at preschool age with peers plays an important role not only in formation of later communication skills, but also for personal development. The lack of movement in some forms of cerebral palsy is so pronounced that, it is impossible to acquire the skills of independent movement and selfsufficiency. In such cases, the education of a child can only be realized at home or boarding school only. A child feels more confident and calm at home which he/she is better familiar with. However, notwithstanding these advantages, home education bears some drawbacks. It is impossible to comprehend human relations in integrity by spending time within family or working with a pedagogue only. The isolation from peers significantly impedes the child socialization, distorts the formation of individual; most of them problems with surrounding people remain unaddressed.

Given the development of information technologies, it is expedient to use distant education technologies for addressing the above mentioned problems of physically disabled persons. Distant education can facilitate the effective search, selection and structuration, as well as the analysis of information by those people. The inclusion of distant education technologies in the education process of disabled people leads to the emergence of new opportunities for the realization of problem-solution and project activity. Hence, personal development and social adaptation of physically disabled children is better facilitated.

Speech therapy. Modern information technologies can be considered among the perspective tools during the rehabilitation of speech disorder diseases in children [8]. The corrective education work in children with development retardation can be carried out with the application of specialized and adapted (education, diagnostic and developmental) computer software tools. The following issues can be posed as primary goals in this case:

- acquiring the skills of computer use; 
- application of information technologies in the correction of psychophysiological disorders.

In last case, it is appropriate to carry out the tasks in the direction of speech breathing, phonations, voice analysis, enriching the vocabulary, removal of lexical and grammatical errors.

The following can be particularly emphasized based on the results obtained in this sphere:

- the purposeful use of computer software tools facilitates the objective and differentiated speech;

- the results of experimental education of children facilitates the harmonization of their development.

Thus, given the research outcomes conducted in this direction of speech therapy, it can be mentioned that the application of computer software can be considered as another method of effective formation of correction of speech defects.

Attention deficit syndrome. One of the major problems of child neurology is the attention deficit syndrome related to hyperactivity. The children with such disorders barely concentrate their attention, hardly control their behavior and cannot focus on one task for a long time. However, they are not mentally underdeveloped as a rule. First signs of hyperactivity in children are observed at 6-7 ages; although attention deficit continues to be present at teen age, the hyperactivity is not observed or severely mitigated in most cases and replaced with activeness, inertness of physical activity and difficulties with waking up [9].

The preparation process of these children for real life, their attention and concentration can be improved with computer games. A problem can emerge to develop a project envisaging the interests and goals of those children by using information technologies (for example, office software, graphic package, voice editors). It can be recommended to carry out works in three directions in hyperactive children: improvement of defected functions (attention, behavior control); development of mutual communication skills with adults and peers; control of anger and naughtiness. Experience shows that, while working on a project, hyperactive children act purposefully. They are observed to increase their confidence and self-esteem.

\section{Main outcomes expected from the formation of e-medicine}

Overall, the following achievements can be expected as a result of e-medicine formation:

- formation of unified national infrastructure and information space;

- opportunity to access the medical data of a person from any point of the world;

- improving the quality of medical services;

- improving the initial prevention;

- detection of disease signs operatively;

- reducing the number of diagnostic and medication appointment errors of doctors;

- optimization of organization of medical services and distribution of resources;

- integration into international systems, etc.

\section{Conclusion}

The level of development of informatics science, Internet facilities, mobile technologies and social networks has a significant impact of various fields of human life and activity. One of those fields is the healthcare system. The development of e-healthcare and e-medicine in accordance with international requirements is a topical problem of the present times. Conducted research, world expertise and the analysis of current period reinforce the vitality of this topic. Hence, consecutive works must be carried out for addressing these issues in our country by considering the international expertise. In case of establishment of successful activity in this field, the formation of unified national e-infrastructure, information space and personalized medicine can be realized. 
This study has been conducted with the financial support of the Science Development Fund under the President of the Republic of Azerbaijan - Grant № EIF-2014-9(24)-KETPL-14/02/1

\section{References}

1. Alguliyev R.M., Alakbarov R.G., Fataliyev T.Kh. Electronic science: current state, problems and perspectives // Information Technologies Problems, 2015, №2, s.4-15.

2. WSIS Forum, 2015, www.itu.int/net4/wsis/forum/2015

3. Fataliyev T.Kh., Verdiyeva N.N., Fataliyeva N.T. Electronic medicine as an integral part of emedicine //"Multidisciplinary problems of electronic medicine" I republican scientificpractical conference, Baku, 24 May 2016, s.;

4. EC Policy eHealth, http://ec.europa.eu/health/ehealth/policy/index_en.htm

5. http://www.itu.int/en/ITU-D/ICT-applications//eHEALTH/Pages/gehealthprojects.aspx

6. Hood L. Systems biology and p4 medicine: past, present, and future // Rambam Maimonides Med., 2013, Vol. 4 (2), pp. 16-23.

7. Oskoui M., Coutinho F., Dykeman J., Jetté N., T. Pringsheim. An update on the prevalence of cerebral palsy: a systematic review and meta-analysis // Developmental Medicine \& Child Neurology, June 2013, Volume 55, Issue 6, pp.509-519.

8. Lazebnik T.A. et al. Correction of speech disorders in children of preschool age with the use of Pantocalcin // Effective pharmacotherapy and pediatrics, 2010, №1, pp. 12-16.

9. Zavadenko N.N. Hyperactivity and attention deficit in children, M.: "Akademia", 2005, p. 256 